\title{
Risk of acute myocardial infarction after transurethral resection of prostate in elderly
}

\author{
Claudio de Lucia ${ }^{1 \dagger}$, Grazia Daniela Femminella ${ }^{1 \dagger}$, Giuseppe Rengo ${ }^{1,2}$, Antonio Ruffo ${ }^{3 *}$, Valentina Parisi ${ }^{1}$, \\ Gennaro Pagano ${ }^{1}$, Daniela Liccardo ${ }^{1}$, Alessandro Cannavo ${ }^{1}$, Paola lacotucci ${ }^{1}$, Klara Komici ${ }^{1}$, Carmela Zincarelli ${ }^{2}$, \\ Carlo Rengo ${ }^{1,2}$, Pasquale Perrone-Filardi ${ }^{4}$, Dario Leosco ${ }^{1}$, Fabrizio lacono ${ }^{3}$, Giuseppe Romeo ${ }^{3}$, Bruno Amato ${ }^{5}$, \\ Nicola Ferrara ${ }^{1,2}$
}

From 26th National Congress of the Italian Society of Geriatric Surgery

Naples, Italy. 19-22 June 2013

\begin{abstract}
Background: Benign prostatic hyperplasia is a frequent disease among elderly, and is responsible for considerable disability. Benign prostatic hyperplasia can be clinically significant due to lower urinary tract symptoms that take place because the gland is enlarged and obstructs urine flow. Transurethral resection of the prostate remains the gold standard treatment for patients with moderate or severe symptoms who need active treatment or who either fail or do not want medical therapy. Moreover, perioperative and postoperative surgery complications as cardiovascular ones still occur. The incidence of acute myocardial infarction in patients undergoing transurethral resection of the prostate is controversial. The first studies showed an increase in mortality and relative risk of death from myocardial infarction in transurethral resection of the prostate group vs open prostatectomy but these results are in contrast with more recent data.

Discussion: Given the conflicting evidence of the studies in the literature, in this review we are going to discuss the factors that may influence the risk of myocardial infarction in elderly patients undergoing prostate surgery. We analyzed the possible common factors that lead to the development of myocardial infarction and benign prostatic hyperplasia (cardiovascular and metabolic), the stressor factors related to prostatectomy (surgical and haemodynamic) and the risk factors specific of the elderly population (comorbidity and therapies).

Summary: Although transurethral resection of the prostate is considered at low risk for severe complications, there are several reports indicating that cardiovascular events in elderly patients undergoing this surgical operation are more common than in the general population. Several cardio-metabolic, surgical and aging-related factors may help explain this observation but results in literature are not concord, especially due to the fact that most data derive from retrospective studies in which selection bias cannot be excluded. Subsequently, further studies are necessary to clarify the incidence of acute myocardial infarction in old people.
\end{abstract}

\section{Background}

Benign prostatic hyperplasia (BPH) is a frequent problem among elderly, and is responsible for significant disability. $\mathrm{BPH}$ is a histological diagnosis that refers to the proliferation of smooth muscle and epithelial cells within the prostatic transition zone. The prevalence and incidence

\footnotetext{
*Correspondence: antonio.ruffo7@gmail.com

† Contributed equally

${ }^{3}$ Department of Urology, Federico II University, Naples, Italy

Full list of author information is available at the end of the article
}

of $\mathrm{BPH}$ increases with aging. Histologic $\mathrm{BPH}$ is present in around $8 \%$ of men aged 31 to $40,50 \%$ of men aged 51 to $60,70 \%$ of men aged 61 to 70 , and $90 \%$ of men aged 81 to 90 . Thereby, symptomatic (clinical) BPH is present in approximately $26 \%$ of men in the fifth decade of life, $33 \%$ of men in the sixth decade, $41 \%$ of men in the seventh decade, and $46 \%$ of men in the eighth decade of life and beyond. BPH can be clinically relevant due to lower urinary tract symptoms (LUTS) that take place because the gland is enlarged and obstructs urine flow. 
Urinary symptoms can include: a frequent, urgent need to urinate, difficulty starting urination, slow (prolonged) urination, nicturia, urinary tract infections, hydronephrosis [1]. The enlarged gland seems to contribute to LUTS via at least two mechanisms: 1) direct bladder outlet obstruction from enlarged tissue (static component) and 2 ) increased smooth muscle tone and resistance within the enlarged gland (dynamic component). Instruments such as the American Urological Association-Symptom Index are now widely utilized to quantify the severity of LUTS in both clinical trials and clinical practice.

The impact of LUTS/BPH on quality of life is very considerable and should not be underestimated [2]. The most important motivations for treatment is symptoms' severity influence on quality life and so the main goal of treatment is to resolve and alleviate storage and voiding symptoms. Hence, treatment has been focused on the amelioration of disease progression and prevention of complications. A variety of pharmacologic classes are used in medical treatment including alpha-adrenergic antagonists (alphablockers), 5-alpha-reductase inhibitors, anticholinergics and phytotherapeutics.

The classic surgical interventions include open prostatectomy (OP) and transurethral resection of prostate (TURP). OP is an invasive surgical procedure that is indicated for men whose prostates, in the point of view of the urologist, are too large for TURP for fear of incomplete resection, significant bleeding or the risk of hyponatremia. TURP remains the gold standard treatment for patients with moderate or severe LUTS who need active treatment or who either fail or do not want medical therapy. TURP was developed during the 1930s as a less invasive alternative to OP in the treatment of benign prostatic enlargement [3]. With increasing worldwide attention on health care costs, minimally invasive therapies for the management of BPH (as Transurethral needle ablation, Transurethral microwave therapy - TUMT, Transurethral incision of the prostate, holmium laser enucleation of the prostate, laser photovaporization of the prostate) will become progressively more important in costeffectiveness evaluations.

However, in the absence of strong evidence favouring newer technologies, TURP currently remains clinically and cost effective. Moreover, TURP peri-operative and postoperative complications still occur. Post-operative complications of TURP are retrograde ejaculation (60-90\% after TURP), urinary tract infections (cause by bacterial colonization of the prostate; occurs in $2 \%$ ), persistent urinary retention ( $2.5 \%$ went home from the hospital with catheter), bladder neck stricture (occurs 2-10\%), urethral stricture (around 10\%; limiting the time of the transurethral catheter), cardiac complications (acute myocardial infarction - AMI). The incidence of AMI in patients undergoing TURP is controversial. The first long-term study by
Roos et al. comprised 54.000 patients from Canada, England and Denmark and showed an increase in mortality of $40 \%$ after a follow-up period of 2-7 years. The relative risk of death from AMI was 2.5 in the TURP group. In addition in this study, TURP was less effective than OP [4].

However some confounding factors could not be ruled since the two populations are not comparable due to the tendency to assign older and less healthy men to TURP because it is less traumatic. Furthermore those studies designed retrospectively did not distinguish possible prognostic factors which were partially responsible for the assignment of the patients to TURP or OP. On the other side, in a study by Shalev at al. there were no differences in the long-term incidence of AMI after open or transurethral prostatectomy. Indeed, AMI developed in the first 3 years after operation in $6.3 \%$ TURP patients compared to $6.9 \%$ OP patients. Neverthless, in men with $\mathrm{BPH}$ after both surgical procedures the incidence of long-term AMI seems to be higher than in the general male population of the same age group [5]. Hahn et al. reported a long-term incidence of AMI of $7.9 \%$ after TURP and of $5.2 \%$ after TUMT. As the incidence of AMI in both study arms was higher than in the general population (standard morbidity ratio: 1.5), the authors proposed that $\mathrm{BPH}$ rather than the treatment itself is associated with cardiovascular disease. The similarity of the results for TURP and TUMT prompts that the prostatic enlargement rather than the treatment is associated with cardiovascular disease [6]. Another study also confirmed a similar mortality or incidences of AMI in TURP group compared to OP at all timepoints (1, 5 and 8 years). Is important to remember the retrospective nature of this analysis and that although age of both groups was identical, the comorbidity rate was slightly ( $25.2 \%$ vs. $21.2 \%)$ higher in the TURP-group [7]. AMI remains the principal cause of hospitalizations as well as the leading cause of death worldwide. In patients with AMI who are older than 70 years, mortality rates exceed $30 \%$ [8]. The incidence and prevalence of MI increase progressively with age. In the United States, over $60 \%$ of AMI occur in patients 65 years of age or older, and approximately one third occur in persons over age 75 [9].

Coronary heart disease is more advanced in the elderly than in younger patients. Three-vessel disease occurred in $44 \%$ of subjects with ischemic heart disease aged $65-74$ and in $63 \%$ of subjects aged 75 and over [10,11].

Heart failure is common in the elderly population. Approximately 6 to 10 percent of the population 65 years or older have heart failure. In patients older than 67 years, median survival is generally less than 3 years after hospitalization for heart failure $[12,13]$. Heart failure is the most common reason for hospitalization in elderly patients. 
Etiology of heart failure is often multifactorial in the elderly [14-16]. The common causes of heart failure include ischemic heart disease, valvular heart disease, hypertensive heart disease, and cardiomyopathy. The complexity in the presentation and in the evolution of heart failure in the elderly leads to research new treatments that can improve the survival of patients with this debilitating disease $[17,18]$.

Given the conflicting results of the studies in the literature on AMI incidence in patients undergoing TURP or $\mathrm{OP}$, in this review we are going to discuss the factors that may influence the risk of AMI in elderly patients undergoing prostate surgery. We therefore decided to analyze the possible common factors that lead to the development of AMI and BPH (cardiovascular and metabolic), the stressor factors related to prostatectomy (surgical and haemodynamic risk factors) and the risk factors specific of the elderly population (comorbidity and therapies).

\section{Discussion}

\section{Cardiovascular and metabolic factors}

Some evidence indicates that the same risk factors associated with heart disease may increase the risk of developing BPH. These risk factors include obesity, diabetes, diet, dyslipidemia, hypertension [19].

Obesity strikingly increases the risk of BPH. The risk of $\mathrm{BPH}$ increases by $10 \%$ for each 0.05 -increase in the waist-to-hip ratio. Increased adiposity is positively related with radiographically determined prostate volume and enlargement, suggesting that obesity promotes prostate growth and rises the risk of clinical BPH and LUTS [20]. Abdominal obesity increases the estrogen-to-androgen ratio and may lead sympathetic overactivity, both hypothesized to influence the development of $\mathrm{BPH}$ and the severity of urinary obstructive symptoms. The increase in adipose aromatization of testosterone to estrogen and the altered levels of testosterone and sex hormone binding globulin in patients with raised adipose stores promote prostatic epithelial and stromal proliferation. Several mechanisms have been proposed to explain the relationship between obesity and increased sympathetic tone. Inflammation with elevated serum concentrations of IL- 6 and TNF-a, increased insulin levels in proportion to the amount of adipose stores and leptin increase have been shown to result in sympathetic overdrive. Furthermore activation of the renin- angiotensinaldosterone system and adrenal alfa2-adrenergic downregulation and desentitation may enhance sympathetic tone [21-25].

Diabetes may also significantly influence the risk of $\mathrm{BPH}$ and LUTS in older men. During insulin-resistance, hyperinsulinemia develops to conuteract the decreased responsiveness of the body to insulin. Although the compensatory hyperinsulinemia prevents development of fasting hyperglycemia in insulin-resistant individuals, the increased level of circulating insulin directly and/or indirectly affects different molecular signaling and can promote prostatic growth. Hyperinsulinemia stimulates the liver to produce more insulin-like growth factor (IGF), another mitogen and an anti-apoptotic agent which binds insulin receptor/IGF receptor and stimulates prostate growth. The levels of IGFs and IGF binding proteins in prostate tissue and in blood are associated with $\mathrm{BPH}$ risk $[26,27]$. It has been demonstrated that a healthy lifestyle plays a critical role in cardiovascular health. It is now apparent that the same is true in the development of BPH. Men with high energy intakes and high intake of protein and polyunsaturated fatty acid were at greater risk of developing BPH [28]. Daily aerobic exercise can ameliorate methabolism, particularly when combined with a low-fat, high-fiber diet consisting of whole grains, fruits, and vegetables. In cell culture studies, this type of lifestyle regimen has recently been shown to reduce the growth of serum-stimulated prostate epithelial cells and the growth of androgendependent prostate cancer cell lines. Alcohol consumption is associated with a decreased likelihood of $\mathrm{BPH}$ but not of LUTS. The association is thought to be related to alcohol's cardiovascular effects and modulation of steroid hormone metabolism [29]. The prostate synthesizes and stores large amounts of cholesterol and prostate tissues may be particularly sensitive to modifications in cholesterol metabolism. Hypercholesterolemia, a major risk factor for cardiovascular disease, is also a risk factor for BPH. Experimental and clinical findings indicate that agents that inhibit cholesterol absorption from the intestine can reduce prostate gland size and improve LUTS [30].

A considerable, age independent association exists between BPH symptoms and hypertension. This finding indicates in increased sympathetic activity a common pathophysiological factor for both disease states [31]. Elderly patients with nicturia had a higher blood pressure and higher serum catecholamine levels compared to healthy elderly controls. Furthermore, hypertension itself seems to have an adverse influence on LUTS and currently used alfa1-adrenergic receptor antagonists (all except tamsulosin), were originally developed as antihypertensive drugs.

\section{Surgical risk factors}

An important stressful factor to the heart during TURP procedure is the fluid excess due to absorption of fluid that enters the circulation via blood vessels in the resection area. Small amounts are probably of little consequence, but the accidental transfer of $>3 \mathrm{~L}$ of fluid results in symptoms originating from the cardiovascular system 
as well as bradycardia and hypotension and sometimes involving the central nervous system with neurologic disturbance as confusion, aggressiveness and depressed consciousness.

The fully developed 'TURP syndrome' is a very rare systemic complication, caused by excessive absorption of electrolyte-free irrigation fluids but mild forms are quite common. The incidence of 'TURP syndrome' has decreased significantly during the last few decades from $3 \%$ to $<1 \%$ but this complication is very dangerous because characterised by symptoms changing from an asymptomatic hyponatremic state to convulsions, coma and death.

Symptoms may occur if the amount of fluid absorbed exceeds 1 litre, which occurs in between 5 and $10 \%$ of the TURPs performed [32]. Normal saline cannot be used as irrigation solution with conventional monopolar resection. Glycine solution is generally used as an irrigation solution in traditional therapeutic endoscopic urologic procedures [33].

The role of irrigation solution is to distend the bladder, clear the surgical site and wash away residual tissue and blood. Various irrigation fluids (glycine, sorbitol, mannitol and normal saline) have been used for TURP. Glycine solution is the most commonly used irrigant in traditional therapeutic endoscopic urologic procedures.

To measure serum electrolytes (sodium and potassium levels) changes during TURP surgery is a simple and economical method for indirect assessment of fluid absorption for early identification of TURP syndrome [34]. Several reports showed that glycine absorption causes neurologic symptoms and echocardiogram changes, as well as T-wave depression or inversion on electrocardiography for up to 24 hours after surgery. Other ECG alterations due to 1.5 glycine absorption are prolongation of the RR interval and QRS duration.

Another significant surgical risk factor during TURP is bleeding and erythrocyte transfusions may subsequently be necessary. Considerable perioperative bleeding will impair the visibility of the surgical field, reduce the tissue elimination and raise hypovolemia risk. Hemorrhages are one of the major intraoperative complications with 1 litre or more blood loss in $14 \%$ of patients $[35,36]$.

Transfusion rate decreased in last ten years from $22 \%$ to $0.4-7.1 \%$. Technological improvements of monopolar and bipolar TURP, microprocessor-controlled units and better instrumentarium resulted in a significant decrease of transfusion rates. Some authors have emphasized the decreased amounts of intra- and postoperative bleeding when the bipolar device is used. The bipolar electrosurgical equipment simultaneously vaporizes the tissue and controls the bleeding. Because TURP syndrome and blood loss are strictly related, Huang et al., showed that bipolar TURP resulted in deeper coagulation zones, less bleeding, less intraoperative hemoglobin drop, smaller serum sodium decrease, and therefore no TURP syndrome occurred [37]. Important bleeding during surgery can be also almost eliminated with alternative energy sources such as the Holmium laser or Potassium Titanyl Phosphate laser.

\section{Hemodynamic factors}

Besides the above mentioned data on TURP and its correlation with AMI incidence, hemodynamic factors have been suggested as potential triggers of myocardial ischemia during TURP. In particular, it has been reported that body temperature lowering due to cold irrigating fluid may result in "cardiac stress" as demonstrated by increased peripheral resistance and arterial pressure, as well as reduced stroke volume and cardiac output after TURP compared to control procedures [38]. Other studies, however, have demonstrated that patients subjected to OP and TURP presented the same degree of hemodynamic alterations, without significant differences, implying that the kind of surgery does not play a relevant role in the late mortality rate of these patients [39]. Further evidence on the hypothesis of TURP-related cardiac stress come from studies evaluating cardiac enzyme levels after this surgical procedure. A slight increases in creatinine kinase- $B$ subunit and lactate dehydrogenase 1 has been reported in patients undergoing TURP, but the criteria for AMI were never fulfilled [40]. More recently, it has been shown that Troponin $\mathrm{T}$ is not increased in patients undergoing TURP without previous cardiac problems. Pro-brain natriuretic peptide is modestly increased but it does not indicate significant ventricular dysfunction [41,42].

Thus, the clinical significance of these increases remains unknown and it is likely that patients with a history of cardiac disease are at a higher risk of myocardial damage during TURP. On the other hand, in elderly patients with no history of heart disease undergoing TURP, continuous ECG Holter monitoring during the pre- intra- and post-operative periods was not able to detect significant variations in electrocardiographical signs indicative for ischemic disease [43].

\section{Comorbidities and therapies}

It is well established that benign prostatic hyperplasia is associated with old age and both OP and TURP are performed in patients with multiple comorbidities. The study by Roos et al. was the first to compare long-term mortality after TURP to OP, showing that TURP resulted in higher long-term mortality compared to OP [4]. However, this study, as mentioned above, was retrospective and confounding factors leading to altered patients' selection could not be ruled. In fact, given the less invasive 
nature of TURP compared to OP, it is likely that patients with multiple comorbidities and higher surgical risk are preferentially referred to TURP, leading to a selection bias that cannot be eliminated in retrospective studies. Moreover, although some studies have confirmed a direct effect of comorbidity on perioperative morbidity and mortality after these procedures [44-46].

Recent evidence indicate that both interventions result in similar cardiovascular outcome. Madersbacher et al. have shown that despite the fact that comorbidity rate was slightly higher in patients undergoing TURP compared to OP, no excess risk of AMI or death after TURP were observed [7]. However, in studies comparing TURP to other mini-invasive techniques, such as TUMT, it has been shown that both interventions are followed by a higher incidence of AMI compared to the general population in patients suffering from various comorbidities (asthma, cardiovascular disease, diabetes) [6]. A recent study specifically evaluated the effect of comorbidities on outcome after TURP and OP indicating that, despite the high prevalence of comorbid conditions in this population, no comorbidity taken alone can be considered an absolute contraindication for these procedures and is associated with the occurrence of complications [47].

Another specific feature of the elderly population is the polypharmacotherapy, that is strictly related to increased comorbidity. Anticoagulant and antiplatelet drugs are widely prescribed in elderly patients, especially those with increased cardiovascular risk. Some studies have evaluated how the management of these drugs can affect outcome in patients undergoing TURP, since stopping anticoagulants prior to TURP may reduce peri-operative blood loss, but it may also increase the risk of cardiovascular events. A recent survey conducted in the United Kingdom has shown that there is a wide variation in stopping aspirin before TURP among urologists [48]. In particular, aspirin is stopped also in patients with increased cardiovascular risk factors, exposing them to the risk of complications. However, a retrospective analysis has indicated that men who have anticoagulation therapy stopped before TURP do not have a higher incidence of cardiovascular, cerebrovascular or thromboembolic events, or bleedings when compared with anticoagulantnaïve patients $[49,50]$. It has also been reported that in patients undergoing TURP a hypercoagulable state can be detected and that surgery itself increases the risk of thrombogenic events [51], thus it is not safe to leave high-risk patients without effective anticoagulation, but to address this issue further studies are needed.

As for lifestyle habits and non-pharmacological interventions, some studies have shown that physical activity may have a protective role on prostatic hyperplasia [52-54]. In particular, it has been observed that an inverse relationship exists between physical activity and prostatic hyperplasia with a risk reduction for both incident surgery and symptomatic cases among nonsedentary men [55-58]. It has been hypothesized that reduction in sympathetic nervous system activity resulting from regular physical training is also able to reduce prostatic smooth muscle tone. In fact, it is well established that aging is associated with altered sympathetic tone and that exercise training has beneficial effects on cardiovascular risk profile in the elderly.

\section{Summary}

Although urological surgery - and TURP in particular - is considered at low risk for subsequent severe complications, there are several reports indicating that cardiovascular events in elderly patients undergoing these procedures are more common than in the general population. Several cardio-metabolic, surgical and agingrelated factors may help explain this observation but the picture still remains confusing, especially due to the fact that most data derive from retrospective studies in which selection bias cannot be excluded. Moreover, recent guidelines suggest to consider patients aged more than 60 years with no history of cardiopulmonary disease at intermediate surgical risk, indicating that age per se plays a role in surgery-specific risk [59].

Thus, the efforts to reduce cardiovascular complications in elderly patients should continue, focusing on better stratification of the risk of atherosclerotic coronary artery disease, detection of the presence of ischemia, and management of surgery-related cardiovascular stressors. In this vein, prospective studies might help clarify unsolved clinical issues and identify pathophysiological mechanisms underlying increased cardiovascular risk in urological elderly patients.

\section{List of abbreviation used}

BPH: benign prostatic hyperplasia; TURP: transurethral resection of prostate; LUTS: lower urinary tract symptoms; OP: open prostatectomy; AMI: acute myocardial infarction; TUMT: transurethral microwave therapy.

\section{Competing interests}

The authors declare that they have no competing interests.

\section{Authors' contributions}

$\mathrm{CdL}$ and GDF: conception and design, final approval of the version to be published; GR, AR,VP,GP, DL, AC, PI, KK, GR: drafting the manuscript, final approval of the version to be published; PPF, DL, FI, NF: revising the manuscript for important intellectual content, final approval of the version to be published.

\section{Declarations}

Publication costs for this article were funded by the Dipartmento di Scienze Mediche Traslazionali, Naples, Italy.

This article has been published as part of BMC Surgery Volume 13 Supplement 2, 2013: Proceedings from the 26th National Congress of the Italian Society of Geriatric Surgery. The full contents of the supplement are available online at http://www.biomedcentral.com/bmcsurg/supplements/13/S2 


\section{Authors' details}

'Department of Translational Medical Sciences, Federico II University, Naples, Italy. ${ }^{2}$ Salvatore Maugeri Foundation, IRCCS - Scientific Institute of Telese Terme, Benevento, Italy. ${ }^{3}$ Department of Urology, Federico II University, Naples, Italy. ${ }^{4}$ Department of Advanced Biomedical Sciences, Federico II University, Naples, Italy. ${ }^{5}$ Department of General, Geriatric, Oncologic Surgery and Advanced Technologies, Federico II University, Naples, Italy.

Published: 8 October 2013

\section{References}

1. Steven A, Kaplan Rev: Update on the American Urological Association Guidelines for the Treatment of Benign Prostatic Hyperplasia. Urol 2006, 8(Suppl 4):S10-S17.

2. Wei J, Calhoun E, Jacobsen S: Urologic diseases in America project: benign prostatic hyperplasia. J Urol 2005, 173:1256.

3. Biester K, Skipka G, Jahn R, Buchberger B, Rohde V, Lange S: Systematic review of surgical treatments for benign prostatic hyperplasia and presentation of an approach to investigate therapeutic equivalence (non-inferiority). BJU Int 2012, 109:722-730.

4. Roos NP, Wennberg JE, Malenka DJ, Fisher ES, McPherson K, Andersen TF, Cohen MM, Ramsey E: Mortality and reoperation after open and transurethral resection of the prostate for benign prostatic hyperplasia. N Engl J Med 1989, 27(320):1120-1124

5. Shalev M, Richter S, Kessler O, Shpitz B, Fredman B, Nissenkorn I: Long-term incidence of acute myocardial infarction after open and transurethral resection of the prostate for benign prostatic hyperplasia. J Urol 1999, 161:491-493.

6. Hahn RG, Farahmand BY, Hallin A, Hammar N, Persson PG: Incidence of acute myocardial infarction and cause-specific mortality after transurethral treatments of prostatic hypertrophy. Urology 2000 55:236-240.

7. Madersbacher S, Lackner J, Brössner C, Röhlich M, Stancik I, Willinger M, Schatzl G, Prostate Study Group of the Austrian Society of Urology: Reoperation, myocardial infarction and mortality after transurethral and open prostatectomy: a nation-wide, long-term analysis of 23,123 cases. Eur Urol 2005, 47:499-504.

8. Devlin W, Cragg D, Jacks M: Comparison of outcome in patients with acute myocardial infarction aged 75 years with that in younger patients. Am J Cardiol 1995, 75:573-576.

9. Rengo F, Leosco D, lacovoni A, Rengo G, Golino L, Borgia F, De Lisa G, Senni M: Epidemiology and risk factors for heart failure in the elderly. Italian Heart Journal 2004, 5(Suppl 10):9-16.

10. Thompson RC, Holmus DR Jr, Gersh BJ, Mock MB, Bailey KR: Percutaneous transluminal coronary angioplasty in the elderly: early and long term results. J Am Coll Cardiol 1991, 17:1245-1250.

11. Piscione F, Cassese S, Galasso G, Cirillo P, Esposito G, Rapacciuolo A, Leosco D, Piccolo R, De Rosa R, Chiariello M: A new approach to percutaneous coronary revascularization in patients requiring undeferrable non-cardiac surgery. Int I Cardiol 2011, 146:399-403.

12. Yamasaki N, Kitaoka H, Matsumura Y, Furuno T, Nishinaga M, Doi Y: Heart failure in the elderly. Intern Med 2003, 42:383-388.

13. Pilotto A, Dallapiccola B, Ferrucci L, Addante F, Franceschi M, Leandro G, Rengo G, Pellegrini F: Multidimensional Prognostic Index based on a comprehensive geriatric assessment predicts short-term mortality in older patients with heart failure. Circ Heart Fail 2010, 3:14-20.

14. Rengo G, Perrone-Filardi P, Femminella GD, Liccardo D, Zincarelli C, de Lucia C, Pagano G, Marsico F, Lymperopoulos A, Leosco D: Targeting the $\beta$-adrenergic receptor system through $G$-protein-coupled receptor kinase 2: a new paradigm for therapy and prognostic evaluation in heart failure: from bench to bedside. Circ Heart Fail 2012, 5:385-391.

15. Rengo G, Lymperopoulos A, Leosco D, Koch WJ: GRK2 as a novel gene therapy target in heart failure. J Mol Cell Cardiol 2011, 50:785-792.

16. Ferrara N, Davia K, Abete P, Rengo F, Harding SE: Alterations in betaadrenoceptor mechanisms in the aging heart. Relationship with heart failure. Aging 1997, 9:391-403.

17. Rengo $G$, Lymperopoulos A, Zincarelli $C$, Femminella $G$, Liccardo $D$, Pagano G, de Lucia C, Cannavo A, Gargiulo P, Ferrara N, Perrone Filardi P, Koch W, Leosco D: Blockade of $\beta$-adrenoceptors restores the GRK2mediated adrenal $\mathrm{a}(2)$-adrenoceptor-catecholamine production axis in heart failure. $\mathrm{Br} J$ Pharmacol 2012, 166:2430-2440.
18. Rengo G, Zincarelli C, Femminella GD, Liccardo D, Pagano G, de Lucia C, Altobelli GG, Cimini V, Ruggiero D, Perrone-Filardi P, Gao E, Ferrara N, Lymperopoulos A, Koch WJ, Leosco D: Myocardial $\beta(2)$-adrenoceptor gene delivery promotes coordinated cardiac adaptive remodelling and angiogenesis in heart failure. Br J Pharmacol 2012, 166:2348-2361.

19. Parsons JK: Modifiable risk factors for benign prostatic hyperplasia and lower urinary tract symptoms: new approaches to old problems. J Urol 2007, 178:395-401.

20. J Parsons JK, Sarma AV, McVary K, Wei JT: Obesity and benign prostatic hyperplasia: clinical connections, emerging etiological paradigms and future directions. Urol 2009, $182(6$ Suppl):S27-31.

21. Meng E: Sympathetic Hyperactivity in Lower Urinary Tract Dysfunction. Incont Pelvic Floor Dysfunct 2010, 4:63-64.

22. Lymperopoulos A, Rengo G, Zincarelli C, Kim J, Koch WJ: Adrenal betaarrestin 1 inhibition in vivo attenuates post-myocardial infarction progression to heart failure and adverse remodeling via reduction of circulating aldosterone levels. J Am Coll Cardiol 2011, 57:356-365.

23. Lymperopoulos A, Rengo G, Zincarelli C, Kim J, Soltys S, Koch WJ: An adrenal $\beta$-arrestin 1-mediated signaling pathway underlies angiotensin II-induced aldosterone production in vitro and in vivo. Proc Natl Acad Sci USA 2009, 106:5825-5830.

24. Lymperopoulos A, Rengo G, Gao E, Ebert SN, Dorn GW II, Koch WJ: Reduction of sympathetic activity via adrenal-targeted GRK2 gene deletion attenuates heart failure progression and improves cardiac function after myocardial infarction. J Biol Chem 2010, 285:16378-16386.

25. Lymperopoulos A, Rengo G, Koch WJ: Adrenal adrenoceptors in heart failure: fine-tuning cardiac stimulation. Trends Mol Med 2007, 13:503-11.

26. Wang Z, Olumi AF: Diabetes, growth hormone-insulin-like growth factor pathways and association to benign prostatic hyperplasia. Differentiation 2011, 82:261-271.

27. Marciano C, Galderisi M, Gargiulo P, Acampa W, D'Amore C, Esposito R, Capasso E, Savarese G, Casaretti L, Lo ludice F, Esposito G, Rengo G, Leosco D, Cuocolo A, Perrone-Filardi P: Effects of type 2 diabetes mellitus on coronary microvascular function and myocardial perfusion in patients without obstructive coronary artery disease. Eur I Nucl Med Mol Imaging 2012, 39(7):1199-206.

28. Suzuki S, Platz EA, Kawachi I, Willett WC, Giovannucci E: Intakes of energy and macronutrients and the risk of benign prostatic hyperplasia. Am J Clin Nutr 2002, 75:689-697.

29. Parsons JK, Im R: Alcohol consumption is associated with a decreased risk of benign prostatic hyperplasia. J Urol 2009, 182:1463-1468.

30. Freeman MR, Solomon KR: Cholesterol and benign prostate disease. Differentiation 2011, 82:244-252.

31. Michel MC, Heemann U, Schumacher H, Mehlburger L, Goepel M: Association of hypertension with symptoms of benign prostatic hyperplasia. J Urol 2004, 172:1390-1393.

32. Hahn RG, Sandfeldt L, Nyman CR: Double-blind randomized study of symptoms associated with absorption of glycine $1.5 \%$ or mannitol $3 \%$ during transurethral resection. J Urol 1998, 160:397-401.

33. Hawary A, Mukhtar K, Sinclair A, Pearce I: Transurethral resection of the prostate syndrome: almost gone but not forgotten. J Endourol 2009, 23:2013-2020.

34. Gupta K, Rastogi B, Jain M, Gupta PK, Sharma D: Electrolyte changes: An indirect method to assess irrigation fluid absorption complications during transurethral resection of prostate: A prospective study. Saudi J Anaesth 2010, 4:142-146.

35. Ekengren J, Collins JW, Macdermott S, Brad RA, Keely FX, Timoney AG: The effects of the choice of irrigating fluid on cardiac stress during Transurethral resection of the prostate: A comparison between 1.5\% Glycine and 5\% glucose. J Urol 2007, 177:1369-1373.

36. Hahn RG: Acute myocardial infarction after transurethral resection of the prostate. Biomed Pharmacother 2001, 55:144-147.

37. Huang X, Wang L, Wang XH, Shi HB, Zhang XJ, Yu ZY: Bipolar transurethral resection of the prostate causes deeper coagulation depth and less bleeding than monopolar transurethral prostatectomy. Urology 2012, 80:1116-1120

38. Evans JW, Singer M, Chapple CR, Macartney N, Walker JM, Milroy EJ: Haemodynamic evidence for cardiac stress during transurethral prostatectomy. BMJ 1992, 304:666-71.

39. D'Addessi A, Perilli V, Ranieri R, Sollazzi L, Crea MA, Racioppi M, Alcini A, Alcini E: Haemodynamic changes detected during open prostatectomy 
and transurethral resection for benign prostatic hyperplasia. Scand I Urol Nephrol 1999, 33:176-80.

40. Hahn RG, Essen P: ECG and cardiac enzymes after glycine absorption in transurethral prostatic resection. Acta Anaesthesiol Scand 1994, 38:550-556.

41. Manikandan R, Nathaniel C, Lewis P, Brough RJ, Adeyoju A, Brown SC, O'Reilly PH, Collins GN: Troponin T and N-terminal pro-brain natriuretic peptide changes in patients undergoing transurethral resection of the prostate. J Urol 2005, 174:1892-1895.

42. Piscione F, Danzi GB, Cassese S, Esposito G, Cirillo P, Galasso G, Rapacciuolo A, Leosco D, Briguori C, Varbella F, Tuccillo B, Chiariello M: Multicentre experience with MGuard net protective stent in ST-elevation myocardial infarction: safety, feasibility, and impact on myocardial reperfusion. Catheter Cardiovasc Interv 2010, 75:715-721.

43. Cançado TO, Leitão FB, Torres ML, Brito FS: Peri-operative evaluation by holter in elderly patients submitted to prostatectomy. Ara Bras Cardiol 2009, 93:409-417.

44. Rengo F, Parisi V, Rengo G, Femminella GD, Rengo C, Zincarelli C, Pagano G, Leosco D: Instruments for geriatric assessment: New multidimensional assessment approaches. Journal of Nephrology 2012, 25:73-78.

45. Ahyai SA, Gilling P, Kaplan SA, Kuntz RM, Madersbacher S, Montorsi F, Speakman MJ, Stief CG: Meta-analysis of Functional Outcomes and Complications Following Transurethral Procedures for Lower Urinary Tract Symptoms Resulting from Benign Prostatic Enlargement. Eur Urol 2010, 58:384-397.

46. Cacciatore F, Gallo C, Ferrara N, Abete P, Paolisso G, Canonico S, Signoriello G, Terracciano C, Napoli C, Varricchio M, Rengo F: Morbidity patterns in aged population in southern Italy. A survey sampling. Arch Gerontol Geriatr 1998, 26:201-213.

47. Marmiroli R, Antunes AA, Reis ST, Nakano E, Srougi M: Standard surgical treatment for benign prostatic hyperplasia is safe for patients over 75 years: analysis of 100 cases from a high-volume urologic center. Clinics (Sao Paulo) 2012, 67:1415-1418.

48. Enver MK, Hoh I, Chinegwundoh Fl: The management of aspirin in transurethral prostatectomy: current practice in the UK. Ann R Coll Surg Engl 2006, 88:280-283.

49. Raj MD, McDonald C, Brooks AJ, Drummond M, Lau HM, Patel MI, Bariol SV, Wang AC, Woo HH: Stopping anticoagulation before TURP does not appear to increase perioperative cardiovascular complications. Urology 2011, 78:1380-1384.

50. Rengo G, Pagano G, Squizzato A, Moja L, Femminella GD, de Lucia C, Komici K, Parisi V, Savarese G, Ferrara N, Perrone-Filardi P, Leosco D: Oral anticoagulation therapy in heart failure patients in sinus rhythm: a systematic review and meta-analysis. PLoS One 2013, 8:e52952.

51. Bell CR, Murdock PJ, Pasi KJ, Morgan RJ: Thrombotic risk factors associated with transurethral prostatectomy. BJU Int 1999, 83:984-989.

52. Rengo G, Galasso G, Vitale DF, Furgi G, Zincarelli C, Golino L, Femminella GD, Piscione F, Rengo F, Leosco D: An active lifestyle prior to coronary surgery is associated with improved survival in elderly patients. J Gerontol A Biol Sci Med Sci 2010, 65:758-763.

53. Leosco D, Rengo G, laccarino G, Golino L, Marchese M, Fortunato F, Zincarelli C, Sanzari E, Ciccarelli M, Galasso G, Altobelli GG, Conti V, Matrone G, Cimini V, Ferrara N, Filippelli A, Koch WJ, Rengo F: Exercise promotes angiogenesis and improves beta-adrenergic receptor signalling in the post-ischaemic failing rat heart. Cardiovasc Res 2008, 78:385-394.

54. Rengo G, Leosco D, Zincarelli C, Marchese M, Corbi G, Liccardo D, Filippelli A, Ferrara N, Lisanti MP, Koch WJ, Lymperopoulos A: Adrenal GRK2 lowering is an underlying mechanism for the beneficial sympathetic effects of exercise training in heart failure. Am J Physiol Heart Circ Physiol 2010, 298:H2032-8.

55. Platz EA, Kawachi I, Rimm EB, Colditz GA, Stampfer MJ, Willett WC, Giovannucci E: Physical activity and benign prostatic hyperplasia. Arch Intern Med 1998, 158:2349-2356.

56. Rinaldi B, Corbi G, Boccuti S, Filippelli W, Rengo G, Leosco D, Rossi F, Filippelli A, Ferrara N: Exercise training affects age-induced changes in SOD and heat shock protein expression in rat heart. Exp Gerontol 2006, 41:764-770.

57. Leosco D, Rengo G, laccarino G, Filippelli A, Lymperopoulos A, Zincarelli C, Fortunato F, Golino L, Marchese M, Esposito G, Rapacciuolo A, Rinaldi B, Ferrara N, Koch WJ, Rengo F: Exercise training and beta-blocker treatment ameliorate age-dependent impairment of beta-adrenergic receptor signaling and enhance cardiac responsiveness to adrenergic stimulation. Am J Physiol Heart Circ Physiol 2007, 293:H1596-603.

58. Giallauria F, Acampa W, Ricci F, Vitelli A, Torella G, Lucci R, Del Prete G, Zampella E, Assante R, Rengo G, Leosco D, Cuocolo A, Vigorito C: Exercise training early after acute myocardial infarction reduces stress-induced hypoperfusion and improves left ventricular function. Eur I Nucl Med Mol Imaging 2013, 40:315-324.

59. Fleisher LA, Beckman JA, Brown KA, Calkins $H$, Chaikof E, Fleischmann KE, Freeman WK, Froehlich JB, Kasper EK, Kersten JR, Riegel B, Robb JF, Smith SC Jr, Jacobs AK, Adams CD, Anderson JL, Antman EM, Buller CE, Creager MA, Ettinger SM, Faxon DP, Fuster V, Halperin JL, Hiratzka LF, Hunt SA, Lytle BW, Nishimura R, Ornato JP, Page RL, Riegel B,

Tarkington LG, Yancy CW: ACC/AHA 2007 guidelines on perioperative cardiovascular evaluation and care for noncardiac surgery: executive summary: a report of the American College of Cardiology/American Heart Association Task Force on Practice Guidelines (Writing Committee to Revise the 2002 Guidelines on Perioperative Cardiovascular Evaluation for Noncardiac Surgery). Anesth Analg 2008, 106:685-712.

doi:10.1186/1471-2482-13-S2-S35

Cite this article as: de Lucia et al:: Risk of acute myocardial infarction after transurethral resection of prostate in elderly. BMC Surgery 2013 13(Suppl 2):S35.

\section{Submit your next manuscript to BioMed Central and take full advantage of:}

- Convenient online submission

- Thorough peer review

- No space constraints or color figure charges

- Immediate publication on acceptance

- Inclusion in PubMed, CAS, Scopus and Google Scholar

- Research which is freely available for redistribution

Submit your manuscript at www.biomedcentral.com/submit
C Biomed Central 